\title{
Drug Stock Prediction at Balige HKBP Hospital Using Adaptive Neuro-Fuzzy Inference System
}

\author{
Arie Satia Dharma ${ }^{1)^{*}}$, Lily Andayani Tampubolon ${ }^{2)}$, Daniel Somanta Purba ${ }^{3)}$ \\ 1)2)3) Institut Teknologi Del, Indonesia \\ 1) ariesatia@gmail.com, ${ }^{2}$ lilyatb@gmail.com, ${ }^{3)}$ danie196@gmail.com
}

Submitted : Mar 18, 2020 | Accepted : Sep 13, 2020 | Published : Oct 1, 2020

\begin{abstract}
The purchases of drugs at Hospital Pharmacy Installation HKBP Balige are based on the examination of the amount of drugs usage. The system purchases of drugs have caused frequent unplanned drugs purchases that must be hastened (cito) and purchases to other pharmacies. The purchases of cito and purchases to other pharmacies will inflict a financial loss to the patients, because when hospital makes drugs purchases of cito or to other pharmacies, the cost of the drugs will be more expensive. Therefore, in this research, a prediction of drugs stock at Hospital Pharmacy Installation HKBP Balige using Adaptive Neuro-Fuzzy Inference System will be carried out. With the hope that this prediction can help in planning drug purchases at hospital of HKBP Balige. ANFIS is a combination of Least Square Estimator and Error-Back Propagation algorithms. The method consists of forward pass and the backward pass learning. The sample data used to predict drugs stock in this research is data of drugs sales from 2013 to 2015. From the results of drugs stock prediction research obtained that number of errors model is $5.52 \%$. Based on Mean Absolute Percentage Error accuracy level evaluation, number of errors have an excellent rate so that it can be concluded that the predicted results of the drugs stock are good.
\end{abstract}

Keywords: ANFIS; MAPE; Hospital; Pharmacy; Drugs; Prediction

\section{INTRODUCTION}

Hospital is a health service institution that carries out complete personal health services (complete) which provides inpatient, outpatient and emergency services. One of the health service units in the hospital is the Hospital Pharmacy Installation (HPI). This is a unit or division or facility in a hospital, the place where all pharmaceutical work activities are carried out intended for the hospital's needs.

Management of medicines is one important component in the HKBP Balige Hospital Pharmacy Installation. During this time, the management of drugs carried out at the Pharmacy Installation of HKBP Balige Hospital based on check the amount of drug use. When the amount of medicine is almost gone then drug purchases will be made. Management of the drug in this way results frequent unplanned drug purchases that must be rushed (cito) and purchase of drugs to an outside pharmacy. Purchasing cito and buying drugs to an outside pharmacy will harm the patient. This is because when the hospital makes a cito purchase or purchases to an outside pharmacy, the cost of buying the drug will be more expensive. The cost of purchasing increasingly expensive drugs will be attributed to the patient.

In this study a prediction will be made to overcome the problems in the management of drugs in the HPI. The prediction that will be carried out is the prediction of the number of drug stocks in the coming year. Predictions are carried out to support the process of analysis and decision making that precedes action control.

The prediction that will be carried out is one of the applications of the soft computing methodology. Soft computing is a collection of methodologies that aim to exploit tolerance to inaccuracies and uncertainties in order to achieve tractability (easy to manage and control), resilience, and the cost of cheap solutions. Soft computing is chosen because soft computing is a collection of methodologies, so the combination of methodologies is expected to predict complex models with high accuracy and forecasting (Dewi \& Himawati, 2015) and can produce a system capable of continuous learning. The soft computing methodology used to make predictive models of drugs in HPI is ANFIS (Adaptive Neuro-Fuzzy Inference System). ANFIS is a neuro-fuzzy approach, which is a combination 
of fuzzy inference systems and artificial neural networks (Cevik \& Cunkas, 2015)(Stojcic, 2018). With the ANFIS method, it is expected that predictions will be made to produce accurate predictions of drug stock.

\section{Adaptive Neuro Fuzzy Inference System (ANFIS)}

\section{LITERATURE REVIEW}

ANFIS is a combination of fuzzy inference systems and artificial neural networks. By using procedures in hybrid learning, ANFIS can build an input-output mapping based on human knowledge (in the form of fuzzy ifthen rules) and specified input-output data pairs (Abdel-Aleem et al, 2017) (Sremac et al, 2018)(Vinsensia \& Utami, 2018). Hybrid method is a combination of EBP (Error Back-Propagation) and LSE (Least-Square Estimator) methods. EBP is used to update parameter values from fuzzy membership functions that are non-linear in nature to output. Whereas LSE is used to update linear parameters to output. The LSE method is carried out in the fourth layer at the advanced stage of the ANFIS structure and the EBP method is carried out at the first layer in the backward stage of the ANFIS structure (Tavana et al, 2016).

There are 2 pass learning in the hybrid method, namely the forward and backward pass.

1. Forward Pass

\section{a. Layer 1}

This layer is the fuzzification layer. At this layer each adaptive i node (can change) to the parameters of an activation function. The output of each node is the degree of membership given by the input membership function, namely $\mu A_{1}(x), \mu A_{2}(x), \mu A_{3}(x)$. The function of the node in this layer is:

$$
O_{1, i}=\mu A_{i}(x) \text {, for } i=1,2,3
$$

The membership degree function in this layer uses the Generalized-Bell function as follows:

$$
\mu A_{i}(x)=\frac{1}{1+\left|\frac{x-S}{\bar{X}}\right|^{2 b}}
$$

with:

$x$ : input data

$\{\bar{X}, b, S\}$ : set of parameters, usually $b=1$. When the values of these parameters change, then the shape of the formed curve will also change. These parameters are called the premise parameters.

b. Layer 2

Each node in this layer is a non-adaptive (fixed) node. In layer 2 the multiplication operation (AND) applies between the fuzzification values of the previous layer. The input data used in this study is only one input so that there is no multiplication operation (AND) the incoming signal. This layer output equation is:

c. Layer 3

$$
O_{2, i}=w_{i}=\mu A_{i}(x) \text {, for } i=1,2,3
$$

Each node in this layer is a fixed node which is the result of calculating the ratio of the rules of the degree of membership to the number of all rules of membership degree, so that it can be formulated as follows:

$$
O_{3, i}=\widehat{w}_{i}=\frac{w_{i}}{w_{1}+w_{2}+w_{3}}, \text { for } i=1,2,3
$$

This result is called normalized firing strength.

d. Layer 4

All nodes in this layer are adaptive nodes with node functions:

$$
O_{4, i}=\widehat{w}_{i} f_{i}=\widehat{w}_{i}\left(p_{i} x+q_{i}\right)
$$

With $\widehat{w}_{i}$ is the normalization of the degree of activation in the layer 3 and $p_{i}, q_{i}$ are the parameters in the layer 4 node. These parameters are called consequent parameters. The consequent parameters are searched using the LSE (Least-Square Estimator) method. In this layer, matrix A is obtained as follows:

$$
\left.\mathrm{A}=\left[\begin{array}{cccccc}
\widehat{w}_{1} x & \widehat{w}_{1} & \widehat{w}_{2} x & \widehat{w}_{2} & \widehat{w}_{3} x & \widehat{w}_{3} \\
\vdots & \vdots & \vdots & \vdots & \vdots & \vdots \\
\widehat{w}_{1} x & \widehat{w}_{1} & \widehat{w}_{2} x & \widehat{w}_{2} & \widehat{w}_{3} x & \widehat{w}_{3}
\end{array}\right]\right\} \text { data } n t h
$$

The number of rows from matrix A is the number of entries $\mathrm{x}$. The LSE method equation for finding consistent parameter value $\theta\left(p_{1}, q_{1}, p_{2}, q_{2}, p_{3}, q_{3}\right)$ is:

$$
\theta=\left(A^{T} \cdot A\right)^{-1} \cdot A^{T} \cdot y
$$

with:

$y=$ desired output or target (actual data)

$T=$ transpose matrix

So that the parameters are obtained: 


$$
\theta=\left[p_{1}, q_{1}, p_{2}, q_{2}, p_{3}, q_{3}\right]^{T}
$$

Next to calculate the output from the layer 4 , the equation used is:

$$
\widehat{w}_{i} f_{i}=\widehat{w}_{1}\left(p_{i} x+q_{i}\right)
$$

e. Layer 5

The node in the layer 5 is a single fixed node that calculates output by adding up all inputs. Here is the function node equation used in the fifth layer.

$$
O_{5, i}=y^{\prime}=\sum_{i} \widehat{w}_{i} f_{i}=\frac{\sum_{i} w_{i} f_{i}}{\sum_{i} w_{i}}
$$

\section{Backward Pass}

The EBP method is used to correct network output errors. The EBP method is used to make improvements to the premise parameters $(\bar{X}$ dan $S)$. If $\varepsilon_{\mathrm{ij}}$ states error in the $j$ th node in the $i$ layer then calculation of the error in each node at each layer is formulated as follows (Hani'ah, 2015).

a. Error in layer 5

In layer 5 there is one node. EBP that goes to this layer is formulated:

$$
\varepsilon_{5 \mathrm{j}}=-2\left(y-y^{\prime}\right)
$$

where $y$ is the output target (actual data), $y^{\prime}$ is the output network ( predicted data) dan $\varepsilon_{5 \mathrm{j}}$ is error in layer 5 .

b. Error in layer 4

In layer 4, there are three nodes. EBP that goes to this layer is formulated:

$$
\varepsilon_{4 \mathrm{j}}=\varepsilon_{5 \mathrm{j}}(1)=\varepsilon_{5 \mathrm{j}}
$$

where $\varepsilon_{4 \mathrm{j}}$ is error in layer 4 .

c. Error in layer 3

In layer 3, there are three nodes. EBP that goes to this layer is formulated:

$$
\varepsilon_{3 \mathrm{j}}=\varepsilon_{4 \mathrm{j}} f_{\mathrm{i}}
$$

where $\varepsilon_{3 \mathrm{j}}$ is error in layer 3 dan $f_{\mathrm{i}}$ is a set of consequent parameters in layer 4 at the forward pass.

d. Error in layer 2

In layer 2, there are three nodes. EBP that goes to this layer is formulated:

$$
\varepsilon_{2 \mathrm{j}}=\varepsilon_{3 \mathrm{j}} \cdot \frac{w_{i}}{\left(w_{1}+w_{2}+w_{3}\right)^{2}}
$$

with $\varepsilon_{2 j}$ is error in layer 2 dan $w_{i}$ is the result of calculating the normalization of the layer 3 at the forwars pass.

e. Error in layer 1

In layer 1, there are three nodes. EBP that goes to this layer is formulated:

$$
\varepsilon_{1 \mathrm{j}}=\varepsilon_{2 \mathrm{j} .} \mu A_{i}(x)
$$

with $\varepsilon_{1 j}$ is error in layer 1 and $\mu \mathrm{A}_{\mathrm{i}}(\mathrm{x})$ is Generalized-Bell's membership functions.

If the error in layer 1 has been obtained, then to get the new Generalized-Bell function the equation is used:

$$
\left(\mu A_{i}(x)\right)^{\prime}=\mu A_{i}(x)+\varepsilon_{1 \mathrm{j}}
$$

The Generalized-Bell function is the layer 1 membership level fuction at the ANFIS forward pass. To find the new set of parameters, namely mean $(\bar{X})$ and deviation standard $(S)$, the equation is used:

$$
\begin{array}{r}
\bar{X}_{\text {baru }}=\bar{X}_{\text {lama }}+\frac{2 b}{\bar{X}_{\text {lama }}}\left(\mu A_{i}(x)\right)^{\prime}\left(1-\left(\mu A_{i}(x)\right)^{\prime}\right) \\
S_{\text {baru }}=S_{\text {lama }}+\left\{\begin{array}{l}
-\frac{2 b}{x-S_{\text {lama }}}\left(\mu A_{i}(x)\right)^{\prime}\left(1-\left(\mu A_{i}(x)\right)^{\prime}\right), \text { jika } x \neq c \\
0, \quad, j i k a x=c
\end{array}\right.
\end{array}
$$




\section{Mean Absolute Percentage Error (MAPE)}

To calculate the accuracy of this method, the calculation of MAPE is used. MAPE is calculated using absolute errors in each period divided by the actual value of the period. Then mean the absolute percentage error. MAPE is a measurement of errors that calculates the percentage percentage deviation between actual data and predicted data. The equation for calculating MAPE (Margi \& Pendawa, 2015) is:

with:

$$
\mathrm{MAPE}=\frac{1}{n} \sum_{i=1}^{n}\left|\frac{y_{i}-y_{i}^{\prime}}{y_{i}}\right| 100 \%
$$

$y_{i}$ : actual output value

$y_{i}^{\prime}$ : prediction output value

$n$ : the number of data

Accuracy of the predictive value can be evaluated based on the significance range (Rokhtiti, 2017) in Table 1:

Table 1

Evaluation Of Accuracy Levels With MAPE

\begin{tabular}{cc}
\hline \hline Percentage & Percentage Evaluation \\
\hline$<10 \%$ & Excellent \\
$10-20 \%$ & Good \\
$20-50 \%$ & Reasonable \\
$>50 \%$ & Bad
\end{tabular}

\section{Data Analysis}

\section{METHOD}

The dataset used to predict drug stock is data on the number of drug sales in HKBP Balige General Hospital in 2013 to 2015. Data on the sale of this drug are the sales of drugs sold to patients. From the sales data of this drug can be known the number of drugs purchased by patients each year so that the number of drugs can be grouped into clusters (high, medium or low).

In the dataset, there are several drugs that have $\mathrm{NaN}$ values. The drug is $\mathrm{NaN}$ because the drug is not purchased in one year. For example, there was one type of drug that was Azitromicin which was not purchased in 2013, but was purchased in 2014. Azitromicin was not purchased in 2013 will cause the absence of Azitromicin data stored in the 2013 dataset. Azitromicin data for 2014 was stored in the dataset. The existence of stored and unsaved data will cause no number of matrix datasets to be used to predict. The number of unequal datasets matrix will cause the dataset cannot be processed to make predictions on the MATLAB R2017b development tool. Therefore, the $\mathrm{NaN}$ value in the dataset is categorized as missing data. Data that is 0 in the dataset is not categorized as missing data, because the data for the drug is stored in the dataset. The number of missing data contained in the dataset can be seen in Table 2. Missing data on this study will be overcome by the KNN algorithm so that the amount of drug data per year is 2519 types of drugs.

Table 2

The Number Of Types Of Drugs And The Number Of Missing Data in The Dataset

\begin{tabular}{ccc}
\hline \hline Year & $\begin{array}{c}\text { Number types of } \\
\text { drugs in dataset }\end{array}$ & $\begin{array}{c}\text { Number missing } \\
\text { data } \text { in } \text { dataset }\end{array}$ \\
\hline 2013 & 1853 types & 666 types \\
2014 & 1642 types & 877 types \\
2015 & 1884 types & 635 types \\
\hline
\end{tabular}

\section{Experiment Design}

The experimental design carried out in this study can be see in Figure 1.

1. Starting from importing the input data that will be used, namely the drug stock data of HKBP Balige Hospital.

2. Perform preprocessing data, namely missing data imputation with $\mathrm{KNN}$ algorithm.

3. After the data from the preprocessing data stage is generated, the input data will be distributed with a percentage of $80 \%$ data train and $20 \%$ data test.

4. Clustering datasets with FCM algorithm. FCM consists of several steps, namely making the initial partition matrix randomly, calculating the cluster center, calculating the objective function, improving the degree of membership and calculating the mean value and standard deviation. 
5. The mean value and standard deviation obtained from clustering will be used to build a fuzzy inference system on ANFIS. ANFIS consists of two stages of learning, namely the forward and backward pass. There are five layers in ANFIS.

6. For forward pass learning, in layer 1, the fuzzification process is carried out. In layer 2, the activation degree is calculated, layer 3 is the activation normalization calculation, layer 4 is defuzzification process, and the layer 5 is the output.

7. As for the backward pass learning, the EBP algorithm is calculated from the layer 5 to the layer 1.

8. Then calculate the MAPE error test value on the output data in the form of prediction results and determine the accuracy level of the MAPE error test value.

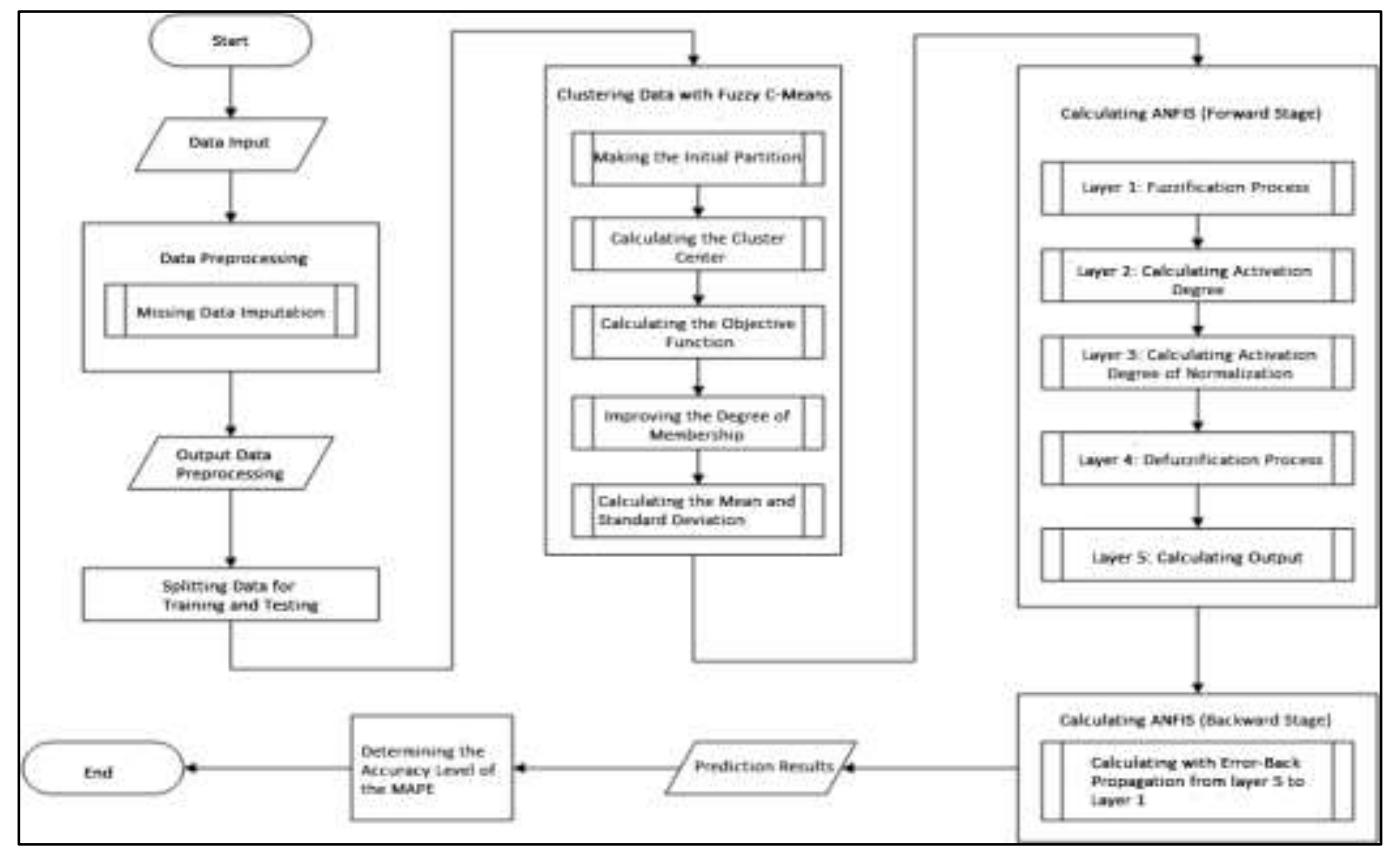

Fig. 1 Design Experiment Schema

\section{Data Preprocessing Experiment Results}

RESULT

Imputation of missing data in this experiment was carried out using 2519 types of drugs. Ten drug samples from the results of the missing data imputation experiment with KNN algorithm can be seen in Table 3 .

Table 3

Imputation Missing Data Experiment Results

\begin{tabular}{clcc}
\hline \hline No & Drugs Name & $\begin{array}{c}\text { Input Data } \\
\text { p'luaran in 2013 }\end{array}$ & $\begin{array}{c}\text { Output Data } \\
\text { p'luaran in 2014 }\end{array}$ \\
\hline 1 & Azitromicin & 292 & 300 \\
2 & Piracetam 3 & 360 & 340 \\
3 & Abilify 15 & 0 & 50 \\
4 & Likurmin & 54 & 132 \\
5 & Urdahex & 1050 & 270 \\
6 & Nald surflo 14 & 0 & 25 \\
7 & Neogynoxa supp & 230 & 200 \\
8 & Dhavit & 106 & 128 \\
9 & Stobled & 752 & 256 \\
10 & Propepsa & 1464 & 745 \\
\hline
\end{tabular}

\section{Clustering Data With Fuzzy C-Means (FCM) Experiment Results}

The FCM initialization data used is the number of clusters $=3$, weighted exponent $=2$, maximum iterations = 100 , and the smallest expected error $=10^{-3}$. The objective function in FCM is used to fulfill the specified error 
condition. When the error condition has been determined, the FCM iteration will stop.Figure 2 shows the error condition $10^{-3}$ fullfilled in the 61 th iterations with objective function $=1493394783.683835$.

The fulfilment of the error conditions $10^{-3}$ in the 61 th iteration produces the degree of cluster center and the degree of membership to build a fuzzy inference system. The data structure of the fuzzy inference system can be seen in Figure 2.

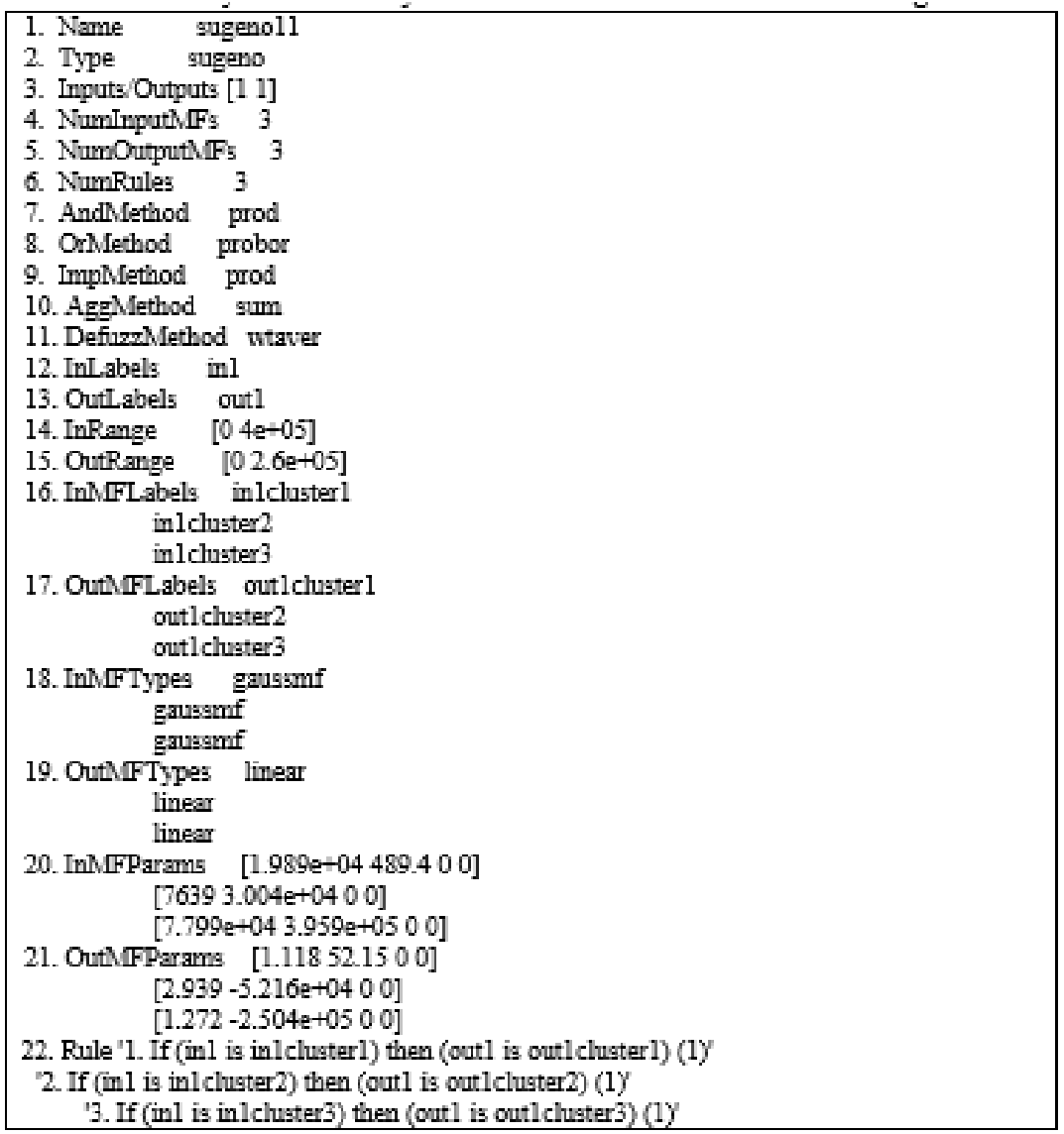

Fig. 2 Structure Of Fuzzy Inference System Generated After Data Clustering With FCM

For rule (rules) fuzzy inference system, in1 is a label of the input data variable in the form of the amount of drug use and out 1 is a label of the output data variable in the form of total usage. in1cluster1, in1cluster2, and in1cluster3, are labels of the input data membership degrees (such as "low", "medium", or "high"). out1cluster1, out1cluster2, and out1cluster3, are labels of membership data output levels (such as "low", "medium", or "high"). in 1cluster1 and out1cluster1 are linguistic labels for low total usage. in1cluster2 and out1cluster2 are linguistic labels for the amount of medium consumption. And in1cluster3 and out1cluster3 are linguistic labels for the high amount of usage.

The translation of the three rules of the fuzzy inference system generated in the clustering data experiment with FCM is:

1. If the input data is low then the data output is low.

2. If the input data is average then the data output is average.

3. If the input data is high then the data output is high.

The input data in the form of the amount of drug use in 2013 and the output data in the form of the amount of drug use in 2014.

Prediction Drugs Stock Using Obat Adaptive Neuro-Fuzzy Inference System (ANFIS) Experiment Results

The ANFIS structure that is formed when predicting drugs stock is done can be seen in Figure 3. 


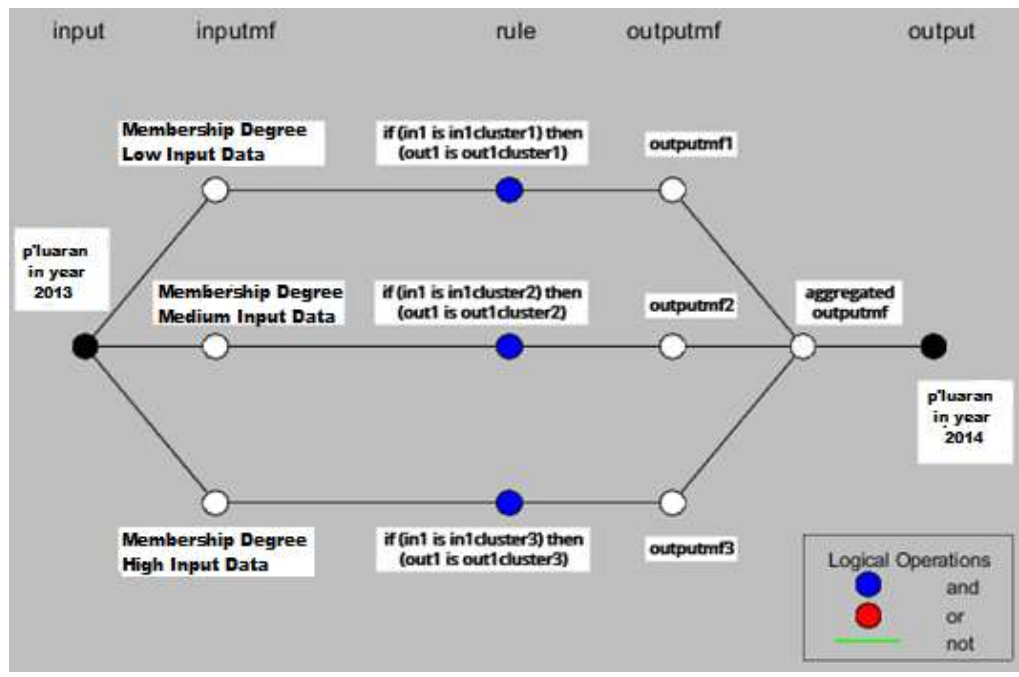

Fig. 3 ANFIS Structure Formed When Predicting Drugs Stock Are Done

The explanation in Figure 3 is as follows:

1. input

In the input there is one input data node, namely the use of electricity in 2013.

2. inputmf

In the fuzzification process, the input data node will be mapped to three inputmf nodes (membership degree) with membership degree function. The first inputmf node is a low input data membership level label. The second inputmf node is the middle level membership data entry label. The third inputmf node is a high input data membership level label.

3. rule

In the process of calculating the degree of activation and normalization of the degree of activation, the three labels of membership degrees that have been mapped will form three rules. The three rules that are formed are if (in1 is in1cluster1) then (out1 is out1cluster1), if (in1 is in1cluster2) then (out1 is out1cluster2) and if (in1 is in 1cluster3) then (out1 is out1cluster3). These three rules use logical and.

4. outputmf

In the defuzzification process there are three outputmf nodes (output data) that are produced, namely outputmf1, outputmf2, and outputmf3.

5. output

The three outputs generated in the defuzzification process will be aggregated so as to produce one final output data which is the prediction of 2014 usage usage.

Experiments on this study were carried out by dividing $80 \%$ data train and $20 \%$ data test from the number of drugs contained in the dataset. From this data distribution, the number of data used as data train as many as 2015 types of drugs was obtained and the amount of data used as test data was 504 types of drugs. Data train results from 10 drug samples can be seen in Table 4. While the results of 10 drug test data can be seen in Table 5.

Table 4

Ten Sample Drugs Data Train

\begin{tabular}{|c|c|c|c|}
\hline No & Drug's Name & $\begin{array}{l}\text { Actual Output Data } \\
\text { p'luaran in year } 2014\end{array}$ & $\begin{array}{l}\text { Predicted Output Data } \\
\text { p'luaran in year } 2014\end{array}$ \\
\hline 1 & Azitromicin & 300 & 323.2653 \\
\hline 2 & Piracetam 3 & 340 & 342.0616 \\
\hline 3 & Abilify 15 & 50 & 50.8284 \\
\hline 4 & Likurmin & 132 & 160.6935 \\
\hline 5 & Urdahex & 270 & 278.3158 \\
\hline 6 & Nald surflo 14 & 25 & 20.8284 \\
\hline 7 & Neogynoxa supp & 200 & 202.4333 \\
\hline 8 & Dhavit & 128 & 133.8802 \\
\hline 9 & Stobled & 256 & 259.8219 \\
\hline 10 & Propepsa & 745 & 733.6437 \\
\hline
\end{tabular}


Table 5

Ten Sampel Drugs Data Test

\begin{tabular}{rlcr}
\hline \hline No & \multicolumn{1}{c}{ Drug's Name } & $\begin{array}{c}\text { Actual Output Data } \\
\text { p'luaran in year 2014 }\end{array}$ & $\begin{array}{c}\text { Predicted Output Data } \\
\text { p'luaran in year 2014 }\end{array}$ \\
\hline 1 & Cerplast Aerofilm 45 x & 30 & 39.6953 \\
& 200 & 72 & 72.6696 \\
2 & Pamol 250 mg supp & 111 & 100.2027 \\
3 & Herbadryl & 10 & 15.4877 \\
4 & Piptal Pediatrik Drops & 20 & 20.8284 \\
5 & Tomaag Forte & 0 & 3.3830 \\
6 & Trifedrin & 48 & 44.5365 \\
7 & Stesolid & 18 & 12.3542 \\
8 & Clinoleic & 100 & 100.2027 \\
9 & Dextrose 5\% $1 / 2$ NS & & \\
\hline
\end{tabular}

The researcher uses the number of MAPE error tests and the level of accuracy to evaluate the experiment. The number of MAPE errors and the level of accuracy can indicate how well the model used in predicting drug stocks. The results of the evaluation of drug stock predictions in the form of the number of MAPE error tests and predictive accuracy levels can be seen in Table 6 .

Table 6

Number Of Error Test MAPE And Accuraccy Level From Experiment Results

\begin{tabular}{cccc}
\hline $\begin{array}{c}\text { Data Split } \\
\text { (Data Train : Data } \\
\text { Test) }\end{array}$ & $\begin{array}{c}\text { Number Of } \\
\text { Cluster }\end{array}$ & $\begin{array}{c}\text { Number Of Error Test MAPE } \\
(\%)\end{array}$ & $\begin{array}{c}\text { Accuraccy } \\
\text { Level }\end{array}$ \\
\hline $80: 20$ & 3 & 5.52 & Excellent \\
\hline
\end{tabular}

The number of MAPE error tests obtained in this experiment is less than $10 \%$ which is $5.52 \%$. The small number of MAPE error tests is influenced by the size of the percentage of deviation between the number of drugs predicted by the actual number of drugs. If the number of drugs predicted is close to the actual number of drugs then the percentage of deviation will be small.

\section{DISCUSSIONS}

Based on the number of MAPE error tests obtained and evaluation of the accuracy level in Table 11, the accuracy level obtained in this experiment is excellent or the model produced to predict very well. The prediction results in this experiment are good because the selection of the right number of clusters in the data clustering. Selection of the right number of clusters will produce the right fuzzy inference system rules.

The smaller the number of MAPE errors a prediction model is, the better the prediction system and the more accurate the prediction results (the number of predictions equals or approaches the actual number of drugs). The number of small MAPE errors will be obtained when the number of rules for the fuzzy inference system is correct. The number of rules in a fuzzy inference system can be determined by the number of clusters. So it can be concluded that the right number of clusters will produce a small number of MAPE errors.

\section{CONCLUSION}

The conclusions of this research is the ANFIS method can be used to predict drug stocks with good accuracy. This accuracy is evaluated based on the level of MAPE accuracy. Determination the exact number of clusters in the clustering data stage with FCM will result in a small number of MAPE errors. The number of small MAPE errors will show good predictions. Based on the experimental results and the constraints found below are suggestions from the author for later consideration and subsequent experiments is try to using drug stock history data with more years because in this final assignment the drug stock history data used to predict only one year.

\section{REFERENCES}

Abdel-Aleem, A., El-Sharief, A. M., Hassan A. M., \& G. El-Sebaie, G. M. (2017). Implementation of Fuzzy and Adaptive Neuro-Fuzzy Inference Systems in Optimization of Production Inventory Problem. Applied Mathematics \& Information Sciences, 11, 289-298. 
Abdulshahed, A., \& Badi, I. (2018). Prediction and control of the surface roughness for the end milling process using ANFIS. Operational Research in Engineering Sciences: Theory and Applications, 1(1), 1-12.

Ambukege, G., Justo, G., \& Mushi, J. (2017). Neuro fuzzy modelling for prediction of consumer price index. International Journal of Artificial Intelligence and Applications, 8, 33-44.

Cevik, H.H., Cunkaş, M. (2015). Short-term load forecasting using fuzzy logic and ANFIS. Neural Comput \& Applic, 26, 1355-1367.

Dewi, C., \& Himawati, W. W. (2015). Prediksi Tingkat Pengangguran Menggunakan Adaptif Neuro Fuzzy Inference System (ANFIS). Konferensi Nasional Sistem \& Informatika 2015, 228-231.

Hani'ah, U. (2015). Implementasi Adaptive Neuro-Fuzzy Inference System (ANFIS) Untuk Peramalan Pemakaian Air Di Perusahaan Daerah Air Minum Tirta Moedal Semarang. Semarang: Universitas Negeri Semarang.

Muchsin, A. K., \& Sudarma, M. (2015). Penerapan Fuzzy C-Means Untuk Penentuan Uang Kuliah Tunggal Mahasiswa Baru. Lontar Komputer, 178.

Margi K., Pendawa S. (2015). Analisa Dan Penerapan Metode Single Exponential Smoothing Untuk Prediksi Penjualan Pada Periode Tertentu. SNATIF, 2, 259-266.

Paul, S. K., Azeem, A., \& Ghosh, A. K. (2015). Application of adaptive neuro-fuzzy inference system and artificial neural network in inventory level forecasting. International Journal of Business Information Systems, 18(3), 268-284.

Pamucar, D., \& Cirovic, G. (2018). Vehicle route selection with an adaptive neuro fuzzy inference system in uncertainty conditions, Decision Making: Applications in Management and Engineering, 1, 13-37.

Rokhtiti, U. (2017). Peramalan Impor Beras Menggunakan Metode Campuran Autoregressive Integrated Moving Average Exogeneous Input dan Adaptive Neuro Fuzzy (ARIMAX-ANFIS) Studi Kasus : Instansi-XYZ. Surabaya: Institut Teknologi Sepuluh Nopember.

Stojcic, M. (2018). Application of ANFIS model in road traffic and transportation: A literature review from 1993 to 2018. Operational Research in Engineering Sciences: Theory and Applications, 1(1), 40-61.

Sremac, S., Tanackov, I., Kopić, M., \& Radović, D. (2018). ANFIS model for determining the economic order quantity. Decision Making: Applications in Management and Engineering, 1(2), 81-92.

Syamsuar, F. (2014). Penerapan Metode Adaptive Neuro Fuzzy Inference System (ANFIS) Untik Peramalan Konsumsi BBM. Pekanbaru: Universitas Islam Negeri Sultan Syarif Kaim Riau.

Tavana, M., Fallahpour, A., Di Caprio, D., \& Santos-Arteaga, F. J. (2016). A hybrid intelligent fuzzy predictive model with simulation for supplier evaluation and selection. Expert Systems with Applications, 61, 129144.

Vinsensia, D., \& Utami, Y. (2018). Penerapan Fuzzy Inference System (FIS) Metode Mamdani dalam Pemilihan Jurusan Perguruan Tinggi. Sinkron : Jurnal Dan Penelitian Teknik Informatika, 2(2), 28-36.

Welinda, R., Sarita, M. I., \& Dewi, A. P. (2016). Implementasi Metode Fuzzy C-Means Pada Sistem Pendukung Keputusan Penentuan Mustahik Di Baznas Kendari. semanTIK, 2(1), 155-168. 